\title{
(죠
}

\section{A Rare Cause of Neck Swelling: Ludwig's Angina} Boyunda Şişliğin Nadir Bir Sebebi: Ludwig Anjini

\author{
Hakan Hasman', Emin Uysal², Serkan Dilmen', Erdem Çevik \\ 'Gülhane Askeri Tıp Akademisi, Acil Tıp Anabilim Dalı, Ankara, Türkiye \\ ${ }^{2}$ Dr. Münif Islamoğlu Devlet Hastanesi, Acil Servis Kliniği, Kastamonu, Türkiye
}

\begin{abstract}
Ludwig's Angina is a rare complication of periodontal infection that can result in severe upper airway obstruction and potentially death. A 22-year-old male presented to the emergency department of a public hospital with fever, chills, left-sided neck pain and swelling. The left submandibular area was indurated with palpable crepitus. Computed tomography showed the extension to deep neck spaces. The patient was treated with ampicillin-sulbactam, metronidazole and analgesics. He was tansported to a tertiary medical center for definitive care. Ludwig's angina is a potentially lethal disease. We believe that many emergency departments have limited experience of the disease because of its rare occurrence. In addition, technical opportunities and early surgery capacity of the emergency room have an effect on survey. Management should contain early diagnosis and the immediate aggressive medical approach. Securing and maintaining the airway is the primary goal in all patients presenting with Ludwig's Angina.
\end{abstract}

Keywords: Ludwig's Angina, neck swelling, upper airway obstruction

Received: 08.05.2011 Accepted: 24.06.2011

\section{ÖZET}

Ludwig Anjini, periodontal enfeksiyonların nadir bir komplikasyonu olan, üst hava yolu tıkanıklığı ve ölümle sonuçlanabilecek bir hastalıktır. Yirmi iki yaşında erkek hasta devlet hastanesinin acil servisine boynunun sol kısmında şişlik, ağı, ateş ve titreme şikayeti ile başvurdu. Hastanın sol submandibular bölgesinde krepitasyon veren şişlik mevcuttu. Bilgisayarlı tomografide derin boyun boşluklarındaki yumuşak dokularda genişleme tespit edildi. Hastaya parenteral ampisilin-sulbaktam, metronidazol ve aneljezik verildi. Genel durumu stabil olan hasta ileri tedavi için 3. basamak sağlık hizmeti veren merkeze nakledildi. Ludwig Anjini, ölümcül bir hastalıktır. Acil servislerde nadir rastlanan bir hastalık olduğu için bu hastalıkla ilgili deneyimlerin sınırlı olduğunu düşünüyoruz. Buna ilaveten acil servislerin teknik imkanları ve erken cerrahi olanaklarının sağ kalımda etkili olduğuna inanıyoruz. Hastalığın yönetiminde erken tanı ve erken agresif tedavi esastır. Daha da önemlisi hava yolunun sağlanması bu hastalarda öncelikli hedef olmalıdır.

Anahtar Kelimeler: Ludwig Anjini, boyunda şişlik, üst hava yolu tıkanıklığı

Geliş Tarihi: 08.05.2011 Kabul Tarihi: 24.06.2011

\section{Giriş}

Ludwig Anjini (LA), ölüme yol açabilecek hava yolu tıkanıklığına neden olan hızlı ilerleyici bir yumuşak doku enfeksiyonudur. LA'nın altında çoğunlukla oral streptekoklar veya aerobik-anerobik oral mukaza flora bakterilerinin neden olduğu periodontal enfeksiyonlar yatar (1). Nadir görülen fakat ölümcül hava yolu obstrüksiyonuna neden olabilen bu hastalığa dikkati çekmek için bu olgu sunumu hazırlanmıştır.

\section{Olgu Sunumu}

Yirmi iki yaşında erkek hasta, devlet hastanesi acil servisine son birkaç gündür olan ateş, titreme, boynunun sol tarafında ağrı ve şişlik şikayeti ile başvurdu. Hasta yaklaşık 1 hafta önce sol alt molar diş ağrısı tarif ediyordu. Hastanın genel durumu iyi görünüyordu. Vital bulguları: Ateş: $38.4^{\circ} \mathrm{C}$, tansiyon arteryel: 100/70 mmHg, nabız: 98/dk, solunum sayısı: 16/dk, oda havasında O2 satürasyonu: \%96 idi. Fizik muayesinde sol submandibular bölgeden başlayan ve boyuna yayılan, yaklaşık $10 \times 10 \mathrm{~cm}$ boyutlarında, palpasyonla hassas, fluktasyon veren ve ısı artışı olan, üzerinde yaygın kızarıklığın olduğu şişlik mevcuttu (Resim 1). Sublingual ve submandibular bölgede şişlik olduğu için dili eleveydi ve orofarenks değerlendirilemedi. Hasta oral sekresyonlarını yutmada zorluk yaşasa da solunum sıkıntısı yoktu. Akciğerlerde dinlemekle ile patolojik ses işitilmedi, stridor yoktu. Diğer sistem mu- 
ayenelerinde patolojik bulgu saptanmadı. Yapılan kan tetkiklerinde

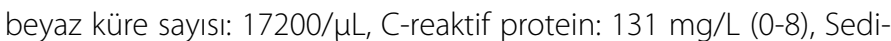
mentasyon: 28/sa (0-20) idi. Çekilen bilgisayarlı tomografide derin boyun boşluklarındaki yumuşak dokularda genişleme tespit edildi (Resim 2). Hastaya 2 gr ampisilin-sulbaktam, 500 mg metronidazol, 500 mg metamizol intravenöz uygulandı. Takibinde vital bulguları normal sınırlar içinde stabil bir seyir izledi. Hasta ileri tedavi için 3. basamak sağlık hizmeti veren bir merkeze nakledildi. Daha sonra hastaya telefonla ulaşıldı. Hastanın nakledildiği merkezde acil serviste bir gün gözlemde tutulduktan sonra ertesi gün, peroral $1 \mathrm{gr}$ ampisilinsulbaktam, 500 mg metronidazol, 500 mg parasetamol tedavisi ile taburcu edildiği öğrenildi.
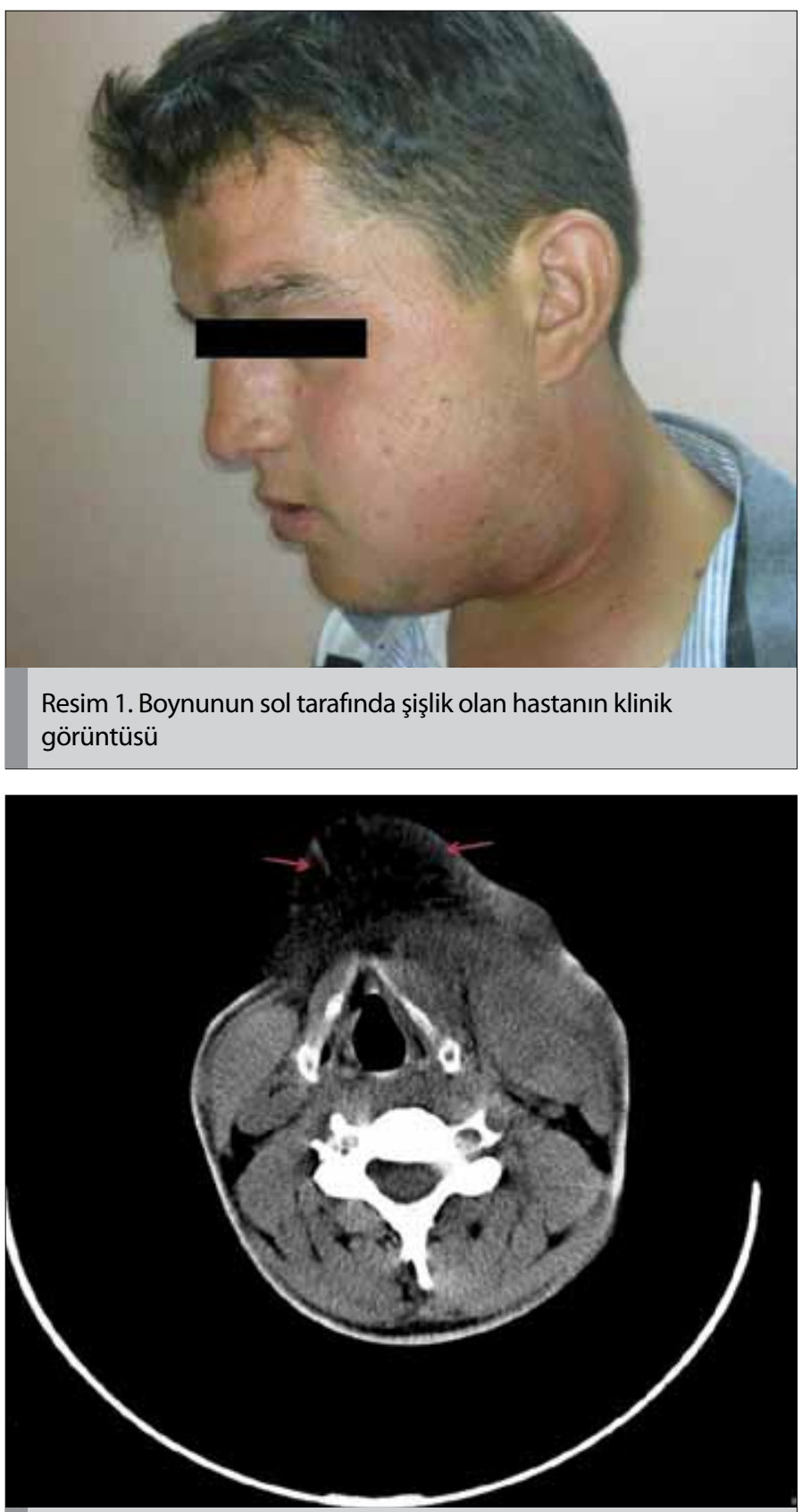

Resim 2. Sol submandibular bölgedeki troid kartilaj seviyesine ulaşan yumuşak doku şişliğinin tomografi görüntüsü

\section{Tartışma}

Ludwig Anjini (LA), ilk kez 1836 yılında Karl Friedrich Wilhelm von Ludwig tarafından tanımlanmıştır (2). LA sublingual, submental ve submandibular bölgeye yayılan, hızlı seyirli bir selülittir. Çoğunlukla yeni çekilmiş veya enfekte olmuş ikinci ve üçüncü molar dişlerden köken alır (3). Bizim hastamız da başvurudan 1 hafta önce olası bir diş enfeksiyonu tarif etmekteydi. LA, hafif bir enfeksiyon olarak başlar ve hızlıca boyuna yayılarak ağrı, trismus ve dilin elevasyonuna neden olur. Ateş ve yutma güçlüğü sıkça görülür. Bizim vakamızda boyun şişliğinin yanında ateş ve yutma güçlüğü vardı. LA'nın en ciddi komplikasyonu boyundaki yumuşak dokulardaki belirgin ödeme bağlı olarak görülen asfiksidir (4). Ölümün bir başka nedeni ise hava yolu sağlamak için yapılan girişimlerdir (5). Stridor, oral sekresyonların kontrolünde zorlanma, anksiyete, siyanoz ve oturma pozisyonu alma hastalığın geç dönem bulgularıdır. Bu bulgular ileri hava yolu yöntemlerine ihtiyaç olduğunu gösterir (6). Bilgisayarlı tomografi, retrofarengeal yayılımı göstermesi açısından yararlıdır (7). Diğer komplikasyonlar ise enfeksiyonun mediastinuma, karotik kılıfa, kafa tabanına ve meningslere yayılımıdır ki bu mortaliteyi \%20'den \%50'ye çıkarır (3). LA, uygun antibiyotik ve cerrahi tedavi uygulamalarına kadar mortalitesi çok yüksek bir hastalıktı (8). Bizim vakamızda hasta medikal tedaviye cevap vermişti. Cerrahi müdahaleye gerek kalmamıştı. Hava yolu tıkanıklığına yol açabileceğinden halen yaşamı tehdit eden bir hastalık olarak karşımıza çıkmaktadır (9). Bu tip vakalarda intravenöz deksametazon ve nebülize adenalin üst hava yolu ödemini gerileterek ileri hava yolu yöntemlerine olan ihtiyacı azaltır (2). Başlangıç olarak 10 mg deksametazon yüklemesinin ardından 48 saat süre ile 6 saatte bir 4 mg deksametazon uygulaması, üst hava yolu ödemini azaltıp antibiyotiklerin penetrasyonunu arttırır $(10,11)$. Nebülize adrenalinin (1 mL 1/1000'lik $1 \mathrm{mg}$ adrenalinin, $5 \mathrm{~mL} \% 0.9 \mathrm{NaCl}$ solüsyonu ile dilüe edilmesi ile hazırlanır) güvenli ve üst hava yolu tıkanıklığının azaltıcı etkisi olduğu düşünülmektedir (12). Etken bakteriler karışık olduğu için yüksek doz penisilin G, metronidazol veya co-amoksilav, klindamisin başlangıç antibiyotik tedavisi için iyi bir seçenektir (13). Tedavi sırasında hasta oturur pozisyonda olmalı ve yalnız bırakılmamalıdır (14). Hastamı ampisilin-sulbaktam ve metronidazol kombinasyonuna cevap vermişir. Fluktasyon veren derin boyun enfeksiyonlarında cerrahi olarak dekompresyon tercih edilen bir yöntemdir (15).

Bozulmuş hava yolu anatomisi, doku immobilitesi ve ağzın sınırlı açılabilmesi orotrakeal entübasyonu zorlaştırmaktadır. Bu tip vakalarda genel anestezi uygulamak tehlikelidir çünkü genel anestezi hava yolunun tam kapanmasını presipite ederken maske ventilasyonu ve entübasyonu imkansız hale getirebilir (13). Körlemesine nazal entübasyon; düşük başarı oranlarının yanında, ciddi kanama, laringospazm, hava yolunda ödem, oral kaviteye rüptür ve aspirasyon gibi komplikasyonları nedeniyle önerilmemektedir (5). Klasik olarak kalıc hava yolu sağlamak için trakeostomi, standart tedavi olarak değerlendirilmektedir. Elektif uyanık trakeostomi uygulaması ciddi hava yolu tıkanıklığı durumlarında acil trakeostomi açmanın tehlikelerinden hastayı kurtaracaktır (9). Ovassapian ve ark. (5) tarafından yapılan çalışmada, toplam 25 fiberoptik entübasyonun tamamı ciddi bir komplikasyon olmadan başarı ile sonuçlanmıştır. Derin boyun enfeksiyonlarında hava yolundaki tüm olumsuzluklar fiberoptik entübasyonu zorlaştırmasına rağmen fiberoptik entübasyondaki ba- 
şarısızığın esas nedenleri hastanın yeterince hazırlanmaması, düşük kalitede fiberoptik cihaz kullanımı ve yetersiz uygulama deneyimidir (16-19).

\section{Sonuç}

Ludwig Anjini tanısının erken konulması ve medikal tedavinin süratle başlatılması, hastanın hava yolunun obstrüksiyonunun önceden fark edilmesinde ve önlenmesinde önemlidir. Acil servislerde nadir rastlanan bir hastalık olduğu için bu hastalıkla ilgili deneyimlerin sınırlı olduğu, buna ilaveten acil servislerin teknik imkanları ve erken cerrahi olanaklarının sağ kalımda etkili olabileceği düşünülmektedir. Acil servislerde, derin boyun enfeksiyonları gibi hava yolu sorunları ile karşılaşılabilecek durumlar için alternatif hava yolu araçlarının bulundurulması bu hasta grubunda mortalite ve morbiditeyi azaltabilecektir.

\section{Çıkar çatışması}

Yazarlar herhangi bir çıkar çatışması bildirmemişlerdir.

\section{Kaynaklar}

1. Topazian RG, Goldberg MH, Hupp JR. Oral and Maxillofacial Infections. 4th ed. Philadelphia, Pa:W.B. Saunders; 2002.

2. Saifeldeen K, Evans R. Ludwig's angina. Emerg Med J 2004; 21: 242-3. [CrossRef]

3. Durand $M$, Joseph $M$. Infections of the upper respiratory tract.In Harrison's Principles of Internal Medicine Volume 1. 16th edition.Edited by: Braunwald E, Fauci AS, Kasper DL, Braunwald E, Hauser S,Longo D, Jameson JL. New York: McGraw-Hill; 2001: 191.

4. Spitalnic SJ, Sucov A. Ludwig's angina: case report and review. J Emerg Med 1995; 13: 499-503. [CrossRef]

5. Ovassapian A, Tuncbilek M, Weitzel EK, Joshi CW. Airway management in adult patients with deep neck infections: A case series and review of the literature. Anesth Analg 2005; 100: 585-9. [CrossRef]
6. Marple BF. Ludwig angina. A review of current airway management. Arch Otolaryngol Head Neck Surg 1999; 125: 596-9.

7. Parhiscar A, Har-EL E. Deep neck abscess. A retrospective review of 210 cases. Ann Otol Rhinol Laryngol 2001; 110: 1051-4.

8. Iwu CO. Ludwig's angina: a report of seven cases and review of current concepts in management. Br J Oral Maxillofac Surg 1990; 28: 189-93. [CrossRef]

9. Barakate MS, Jensen MJ, Hemli JM, Graham AR. Ludwig's angina: report of a case and review of management issues. Ann Otol Rhinol Laryngol 2001; 110: 453-6.

10. Bush RF, Shaha D. Ludwig's angina- improved treatment. Otolaryngol Head Neck Surg 1997; 117: 172-5

11. Freud B, Timon C. Ludwig's angina: a place for steroid therapy in its management. Oral Health 1992; 82: 23-5.

12. MacDonnell SPJ, Timmins AC, Watson JD. Adrenalin administred via a nebuliser in adult patients with upper airway obstruction. Anaesthesia 1995; 50: 35-6. [CrossRef]

13. Parhiscar A, Har-El G. Deep neck abscess: a retrospective review of 210 cases. Ann Otol Rhinol Laryngol 2001; 110: 1051-4.

14. Furst IM, Ersil P, Caminiti M. A rare complication of tooth abscessLudwig's angina and mediastinitis. J Can Dent Assoc 2001; 67: 324-7.

15. Kulkarni AH, Pai SD, Bhattarai B, Rao ST, Ambareesha M. Ludwig's angina and airway considerations: a case report. Cases Journal 2008; 1: 1-19. [CrossRef]

16. Patterson HC, Kelly JH, Strome M. Ludwig's angina: an update.Laryngoscope 1982; 92: 370-8. [CrossRef]

17. McGuire G, El-Beheiry H. Complete upper airway obstruction during awake fiberoptic intubation in patients with unstable cervical spine fractures. Can J Anaesth 1999; 46: 176-8. [CrossRef]

18. Shaw IC, Welchew EA, Harrison BJ, Michael S. Complete airway obstruction during awake fiberoptic intubation. Anaesthesia 1997; 52: 582-5. [CrossRef]

19. Mason RA, Fielder CP. The obstructed airway in head and neck surgery [editorial]. Anaesthesia 1999; 54: 625-8. [ ] 